\title{
Genetic parameters and relationships of faecal worm egg count with objectively measured wool traits in the Tygerhoek Merino flock
}

\author{
P.A.M. Matebesi-Ranthimo ${ }^{1,2}$, S.W.P. Cloete ${ }^{3,4 \#}$, J.B. van Wyk $^{1}$ \& J.J. Olivier ${ }^{4}$ \\ ${ }^{1}$ National University of Lesotho, P.O. Roma 180, Roma, Lesotho \\ ${ }^{2}$ University of the Free State, P.O. Box 339, Bloemfontein 9300, South Africa \\ ${ }^{3}$ University of Stellenbosch, Private Bag X1, Matieland, 7602, South Africa \\ ${ }^{4}$ Directorate of Animal Sciences: Elsenburg, Private Bag X1, Elsenburg, 7609, South Africa
}

(Received 25 March 2013; Accepted 13 May 2014; First published online 9 July 2014)

\author{
Copyright resides with the authors in terms of the Creative Commons Attribution 2.5 South African Licence. \\ See: http://creativecommons.org/licenses/by/2.5/za \\ Condition of use: The user may copy, distribute, transmit and adapt the work, but must recognise the authors and the South African \\ Journal of Animal Science.
}

\begin{abstract}
The costs of internal parasite control and treatment are potentially very high in grazing sheep. Faecal worm egg count (FEC) has been suggested as a suitable criterion for selection for resistance to nematode infestation in livestock. Genetic parameter estimates for FEC and its relationship with wool traits were assessed in the current study, using data from Merino sheep from a selection experiment maintained at Tygerhoek Research Farm. Data consisted of $\sim 7100$ animals born between 1989 and 2010. Rectal faecal samples were taken from individual sheep at 13 to 16 months of age, after drenching had been withheld for at least 10 weeks, generally in July to September. Nematode eggs were counted with the McMaster technique, with a sensitivity of 100 eggs per gram of wet faeces. The fixed effects of birth type, sex, birth year and sex $x$ birth year interaction were included in the operational model for FEC. Only the effect of additive animal affected the data for FEC. Heritability estimates of FEC ranged from 0.10 for untransformed FEC to 0.16 for Log (FEC + 100). The genetic relationships of Log $(F E C+100)$ with staple strength (SS), staple length (SL), coefficient of variation of fibre diameter (CVFD) and standard deviation of fibre diameter (SDFD) were favourable. The genetic correlations of FEC with wool weight traits were unfavourable in absolute terms, but not significantly different from zero. Selection for FEC is unlikely to result in unfavourable correlated responses to wool traits in South African Merinos, with the exception of wool weights.
\end{abstract}

Keywords: Internal parasites, fleece weight, fibre traits, staple traits, correlations, resistance

\# Corresponding author: schalkc@elsenburg.com

\section{Introduction}

Internal parasite infestations constitute a major disease problem for domestic livestock, which poses a threat to sustainable production worldwide (Karlsson et al., 1995; Zhang et al., 1997; Nieuwoudt et al., 2002; Perry et al., 2002; Chauhan et al., 2003). Grazing livestock is often at the highest risk from infection by gastro-intestinal nematode parasites (Bisset et al., 1992; Chauhan et al., 2003). Internal parasites cost sheep producers hundreds of millions of dollars each year (Brown \& Tier, 2003; Khusro et al., 2004) because of expense of treatment, increased level of management and vigilance, loss of production and even mortality in severe cases (Nieuwoudt et al., 2002; Brown \& Tier, 2003; Khusro et al., 2004; Snyman, 2007).

Resistance of gastro-intestinal parasites to anthelmintics has become more prevalent over the past years (Gray, 1991; Eady, 1995; Karlsson et al., 1995; Greeff \& Karlsson, 1999; Nieuwoudt et al., 2002) and is now at a very high level that threatens sustainable control and treatment of internal parasites (Karlsson \& Greeff, 2006; Snyman et al., 2007; Reynecke et al., 2011). In addition, there has been growing concern that consumers demand animal products that are free from contamination of chemicals (Khusro et al., 2004). Research suggested that selection for resistance to nematode infestation and its inclusion into the breeding objectives should receive attention (Gray, 1991; Eady, 1995; Amer et al., 1997; Vatta et al., 2000). Integrated parasite control measures (Karlsson, 1999; Nieuwoudt et al., 2002) may contribute towards reducing the parasite burden in a variety of small ruminants. Gary (1991) identified faecal worm egg count (FEC) as a valuable criterion for improving genetic resistance to gastro-intestinal nematodes. 
As a result, FEC has been widely used to estimate genetic variation in resistance to nematode infestation in sheep (Greeff et al., 1995; Morris et al., 1996; 1997; Cloete et al., 2000; Khusro et al., 2004; Yadav et al., 2006; Cloete et al., 2007; Snyman, 2007) and goats (Mandonnet et al., 2001; Olayemi et al., 2001; Chauhan et al., 2003; Mandal \& Sharma, 2008). Several authors have reviewed genetic parameters for resistance to nematodes in sheep (Safari et al., 2005; Morris, 2011). The evidence of successful Australian (Pocock et al., 1995; Woolaston \& Piper, 1996; Greeff et al., 1999; Greeff et al., 2006) and New Zealand (Bisset \& Morris, 1996; Morris et al., 2005) breeding programmes for resistance and resilience (Morris et al., 2010) to nematode infestation may guarantee economic advantages in South African Merino sheep.

In South Africa, published reports could not be found on breeding programmes for resistance to nematode infestation. However, a few studies estimated genetic parameters for nematode resistance in sheep, using FEC as an indicator trait (Cloete et al., 2000; Bisset et al., 2001; Nieuwoudt et al., 2002; Cloete et al., 2007; Snyman, 2007) with only two publications on genetic correlations of FEC with other traits of economic importance (Cloete et al., 2000; 2007). Other published reports on genetic parameters for nematode resistance used the clinical evaluation of anaemia and body condition score system (Famacha) in South African small ruminants (Van Wyk \& Bath, 2002; Vattaa \& Lindberg, 2006). Current South African published reports on genetic correlations of FEC and other traits do not include all traits of economic importance in wool sheep, such as staple length (SL), greasy fleece weight (GFW), clean yield (CY) and standard deviation of fibre diameter (SDFD). Relationships of FEC with wool traits are limited in the literature. The suggestions by Cloete et al. (2007) for further investigations on genetic parameters for FEC and other traits of economic importance in South African sheep flocks are heeded to owing to the paucity of analyses of FEC data in local sheep flocks.

The objectives of the present study were to estimate the (co)variance components and ratios as well as genetic, phenotypic and environmental correlations between FEC and objectively measured wool traits in South African Merino sheep.

\section{Material and Methods}

Performance records were obtained from four lines (a line selected for clean fleece weight, a fine wool line, an unselected control line, and a line selected against failure to lamb or to rear a lamb per lambing opportunity) of Merino sheep born on Tygerhoek Experimental Farm, Western Cape Department of Agriculture, near Riviersonderend in Western Cape, South Africa. The lines were not genetically linked, but the offspring were managed in the same contemporary group. The animals providing the data were the progeny born between 1989 and 2012. Pedigree records were collected from 1969 to 2012. The data included $\sim 7500$ animals, the progeny of 567 sires and 2605 dams. The origin and initial selection in the flock were first described by Heydenrych (1975) and Heydenrych et al. (1984). Subsequent analyses on animals from the flock involved studies on reproduction (Cloete, 1986), early liveweight, testicular size and reproduction (Duguma, 2002), objective wool traits, subjective wool traits and conformation traits, as well as liveweight at 16 months (Matebesi-Ranthimo, 2007).

There was no direct selection for FEC in any of the lines, as indicated by Cloete et al. (2007). The description of flock maintenance, husbandry, experimental design and sampling procedures for FEC was described by Cloete et al. (2007). The rectal faeces samples were obtained from 1995 to 2012 (with the exception of 2004) from individual animals between the ages of 13 and 16 months. The sampling was conducted after drenching had been withheld for at least 10 weeks, generally in July to September. During this time, animals are likely to be subjected to a mixture of Ostertagia and Trychostrongylus spp. (Cloete et al., 2007). Individual faecal samples were then assessed for FEC at Western Cape Provincial Veterinary Laboratory, using the McMaster technique, with a sensitivity of 100 eggs per gram of wet faeces (Van Schalkwyk et al., 1994).

Traits that were analysed were FEC, greasy fleece weight (GFW), clean fleece weight (CFW), clean yield (CY), fibre diameter (FD), staple length (SL) and staple strength (SS). Two measurements of the variability of FD were included in the analysis, namely standard deviation of FD (SDFD); and coefficient of variation of FD (CVFD). GFW was recorded at shearing in August-September each year, while the measures of quality were determined on a midrib wool sample taken from each animal at $14-16$ months of age. Information on GFW was combined with CY data to derive CFW. Data for FEC were transformed to logarithms to the base of 10 (after a base number of 100 was added to each value to account for zero counts) or to cube roots to improve data distribution. These transformations have been used extensively by a number of researchers to normalize FEC data in Australia (Greeff et al., 1995; Karlsson et al., 1995; Doyle \& Eady, 2001; Brown \& Tier 2003; Pollott \& Greeff, 2004), New Zealand (Morris et al., 1997), India (Yadav et al., 2006), South Africa (Cloete et al., 2007) and the United Kingdom (Matika et al., 2010). Untransformed data and data subjected to the transformations listed above resulted in three analyses on FEC. 
The statistical analysis was done with the ASREML program (Gilmour et al., 2009). Initially the overview observation of the data structure was performed with the objective of identifying the abnormalities and biological feasibility of the records in the datasets. All animals without a sire or dam, birth status or sex were excluded from the analysis. Dams aged 7 years and beyond were pooled together. Triplets and twins were pooled as multiples. All animals without records were excluded from the analysis. Animals with a missing record for a particular trait were excluded from the analysis for that particular trait.

The significance of fixed effects was tested, leaving only significant effects in the final operational model. Fixed effects from the analyses were consistent with those reported in the literature, and thus were not presented and discussed further. The following fixed effects model was fitted for all traits:

$$
Y_{i j k l m n p}=\mu+s_{j}+b t_{k}+a d_{l}+y_{m}+g_{n}+s y_{p}+e_{i j k l m n p}
$$

where $Y_{i j k l m n p}=$ an observation of a trait on the $i^{\text {th }}$ animal of the $j^{\text {th }}$ sex of the $k^{\text {th }}$ birth status from the $I^{\text {th }}$ age of the dam, $\mathrm{m}^{\text {th }}$ birth year, $\mathrm{n}^{\text {th }}$ line and $\mathrm{p}^{\text {th }}$ sex by birth year interaction.

$\mu=$ the overall mean

$s_{j}=$ the fixed effect of the $j^{\text {th }}$ sex $(j=$ ram, ewe)

$\mathrm{bt}_{\mathrm{k}}=$ the fixed effect of the $\mathrm{k}^{\text {th }}$ birth status ( $\mathrm{k}=$ singles, multiples)

$\mathrm{ad}_{1}=$ the fixed effect of the $\mathrm{I}^{\text {th }}$ age of dam class $\left(\mathrm{I}=2,3,4,5,6,7^{+}\right.$years $)$

$y_{m}=$ the fixed effect of the $m^{\text {th }}$ birth year class $(m=89,90,91, \ldots, 110)$

$g_{n}=$ the fixed effect of the $n^{\text {th }}$ line $(n=1,2,3,4)$

$\mathrm{sy}_{\mathrm{p}}=$ the fixed effect of the $\mathrm{p}^{\text {th }}$ sex by birth year interaction $(n=1,2,3, \ldots, 42)$

$\mathrm{e}_{\mathrm{ijk} k \mathrm{mnp}}=$ randomly distributed residual variance used as error term to test the other effects for significance.

The (co)variances components were estimated and obtained by fitting single-trait animal models initially. These models include a combination of direct additive, maternal additive and maternal permanent environmental effects, as well as the covariation between direct additive and maternal additive effects. Six forms of single-trait mixed animal models (in matrix notation) were fitted for all traits:

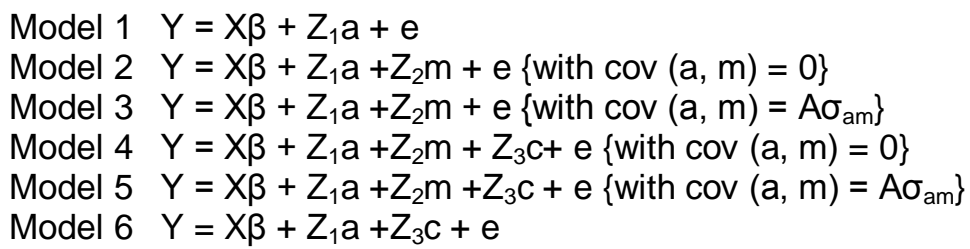

where $Y$ is a vector of observations; $\beta$ is a vector of fixed effects influencing traits; $a, m, c$ are vectors of direct additive, maternal additive (dam) permanent maternal environmental and $\mathrm{e}$ is residual effects, respectively. $X, Z_{1}, Z_{2}$ and $Z_{3}$ are considered incidence matrices relating observations to their respective fixed and random effects. It was assumed that:

$$
V(a)=A \sigma_{a}^{2} ; V(m)=A \sigma_{m}^{2} ; V(c)=I d \sigma_{c}^{2} ; V(e)=I \sigma_{e}^{2}
$$

where $\mathbf{A}$ is the numerator relationship matrix among animals in the pedigree file, and $\mathbf{I}$ is an identity matrix. The variances, $\sigma_{a}^{2}, \sigma_{m}^{2}, \sigma_{c}^{2}, \sigma_{e}^{2}$, were defined as the direct genetic variance, the maternal genetic variance, the permanent environmental variance due to the dam and the residual (error) variance, respectively. The phenotypic variance $\left(\sigma_{p}^{2}\right)$ was defined as the sum of all variance components estimated in the model of analysis, and could be derived from all the above variances, as appropriate for the specific analysis. Heritability estimates were calculated as $\sigma_{a}^{2} / \sigma_{p}^{2}$ and the maternal heritability as $\sigma^{2}{ }_{m} / \sigma_{p}^{2}$.

The significance of the random effects was tested using log likelihood ratio tests after the inclusion of one additional random effect added to the model sequentially. A random effect was considered significant when its inclusion in the model caused a significant improvement in the log likelihood ratio. A chi-square distribution of $\alpha=0.05$ at one degree of freedom was used as a test statistic (3.841). When -2 times the difference between the log likelihoods was greater than this critical value, the inclusion of the particular random effect was considered to significantly improve the fit of the model (Swalve, 1993). The objective of testing the significance of the various models was to identify the best and simplest models that could be used for subsequent runs. Therefore, the model with the least possible number of random effects was used when the inclusion of additional random effects did not significantly improve the observed log likelihood ratio. 
The genetic, environmental and phenotypic correlations between FEC and objectively measured wool traits were estimated by fitting a series of two-trait and four-trait models. Starting values for the (co)variance components of two- and four-trait models were obtained from the single-trait models fitted initially.

\section{Results and Discussion}

The fixed effects of birth type (single/multiple, $P<0.05)$, sex (male/female), year of birth (1989 - 2003, 2005 - 2012) and the sex*birth year interaction had a significant $(P<0.01)$ effect on FEC. Transforming FEC data did not change the significance of the fixed effects. These results are consistent with those reported by Cloete et al. (2007) on the same Merino resource flock. A similar set of fixed effects for FEC, combined with selection line $(1-4)$ and age of dam $\left(2-7^{+}\right)$, significantly affected all objectively measured wool traits, and were included in the models used for subsequent analyses. The least square means depicting the influence of the fixed effects under consideration generally corresponded with those reported in the literature for wool and dual-purpose sheep (Safari et al., 2005). These effects are therefore not reported in detail, because it would duplicate results that have already been well described.

The descriptive statistics reported a considerable variation in the number of records used for the current study, ranging from 3842 for SS to 7274 for FD (Table 1). Untransformed FEC data suggested very high variation and a non-normal distribution, which were similar to findings reported by Pollott \& Greeff (2004), Yadav et al. (2006) and Cloete et al. (2007). However, the application of transformations on data improved their properties to a point that the coefficient of variation was $19.77 \%$ in the log-transformed data. This indicated the need to transform data to improve the distribution. All objectively assessed wool traits were variable in the present study (Table 1 ). The wool quality traits CY and FD showed lower levels of variation $(<11 \%)$ than the other objectively measured wool traits.

Table 1 Descriptive statistics of data used after editing from a Tygerhoek Merino resource flock $(n=$ number of records, $\mathrm{SD}=$ standard deviation and $\mathrm{CV}=$ coefficient of variation)

\begin{tabular}{|c|c|c|c|c|c|c|}
\hline Trait & $\mathbf{N}$ & Mean & SD & CV (\%) & Minimum & Maximum \\
\hline \multicolumn{7}{|c|}{ Faecal egg count traits (eggs per gram wet faeces) } \\
\hline Faecal worm egg count (FEC) & 5891 & 660.3 & 1203.0 & 182.27 & 0 & 32700 \\
\hline FEC $(\log +100)$ & 5891 & 2.57 & 0.508 & 19.77 & 2.000 & 4.516 \\
\hline FEC (cube root) & 5891 & 5.879 & 4.883 & 83.06 & 0 & 31.98 \\
\hline \multicolumn{7}{|l|}{ Objective wool traits } \\
\hline Greasy fleece weight $(\mathrm{kg})$ & 7273 & 4.96 & 1.24 & 25.00 & 1.0 & 9.4 \\
\hline Clean fleece weight $(\mathrm{kg})$ & 7273 & 3.56 & 0.91 & 25.56 & 0.7 & 7.0 \\
\hline Clean yield (\%) & 7273 & 71.97 & 4.61 & 6.41 & 49.9 & 98.4 \\
\hline Staple length $(\mathrm{mm})$ & 7000 & 91.10 & 15.23 & 16.72 & 33.0 & 144.1 \\
\hline Staple strength (N/Ktex) & 4294 & 34.81 & 12.25 & 35.19 & 2.0 & 77.0 \\
\hline Fibre diameter $(\mu \mathrm{m})$ & 7274 & 19.15 & 2.06 & 10.76 & 13.2 & 27.6 \\
\hline CV of fibre diameter (\%) & 6133 & 19.41 & 2.88 & 14.84 & 11.9 & 39.0 \\
\hline SD of fibre diameter $(\mu \mathrm{m})$ & 6133 & 3.69 & 0.74 & 20.05 & 2.1 & 6.8 \\
\hline
\end{tabular}

FEC: untransformed faecal worm egg count data; FEC (Log+100): log-transformed data + 100 to cater for 0. FEC (cube root): cube-root-transformed data.

An appropriate random effects model is important for the accurate estimation of genetic parameters in livestock (Van Wyk et al., 2003). The model with only the direct additive $\left(\sigma^{2}{ }_{a}\right)$ effect fitted the data best for all the FEC traits in the present study (Table 2). A similar random model was used in Australian Merinos (Pollott \& Greeff, 2004). However, Cloete et al. (2007) fitted a different random model including both $\sigma^{2}{ }_{a}$ and dam permanent environmental effects $\left(\sigma^{2}\right.$ pe) on the same Merino resource flock. In addition, Khusro et al. (2004) fitted different random effects models with $\sigma_{a}^{2}$ and maternal additive $\left(\sigma_{m}^{2}\right)$ effects on Australian Merinos, but did not partition the maternal variance into $\sigma_{m}^{2}$ and $\sigma^{2}$ e. The inclusion of only additive genetic variance fitted the data best for CY, SL, SS, CVFD and SDFD. A substantial number of these researchers did not find any maternal influence on the expression of corresponding traits on various sheep breeds. Maternal effects in 
addition to $\sigma_{a}^{2}$ were present in the FD analysis, while the covariance between animal effects $\left(\sigma_{a m}\right)$ as well as $\sigma_{\text {pe }}^{2}$ contributed to the variation of GFW and CFW. Several studies reported significant $\sigma_{m}^{2}$ effects on wool weights in various sheep breeds. In contrast, Vaez Torshizi et al. (1996) reported no significant $\sigma_{m}^{2}$ for any of the corresponding wool traits beyond 12 months of age. Some studies also reported the $\sigma^{2}{ }_{p e}$ having a significant effect on FD. However, Safari et al. (2007b) found a significant $\sigma_{m}^{2}, \sigma_{a m}, \sigma_{p e}^{2}$ as well as a litter effect on 14 - 17 months of age for GFW, CFW, FD, CY, SDFD and CVFD. The literature and the results from this investigation strongly indicate that more random effects should be considered during the analysis of models for FEC and also for some of the objectively measured wool traits.

Table 2 Log likelihood ratios for random effects model fitted to FEC and objectively measured wool traits data of Tygerhoek Merino resource flock with "best" model in bold

\begin{tabular}{ccccccc}
\hline & Model 1 & Model 2 & Model 3 & Model 4 & Model 5 & Model 6 \\
\hline Faecal egg count traits & & & & & & \\
FEC & $\mathbf{- 3 6 3 0 . 4 4}$ & -3630.14 & -3629.76 & -3630.14 & -3629.75 & -3630.33 \\
FEC(cube root) & $\mathbf{- 5 0 2 0 . 8 2}$ & -5020.53 & -5020.51 & -5020.53 & -5020.51 & -5020.74 \\
FEC(Log+100) & $\mathbf{2 5 7 8 . 4 5}$ & 2579.74 & 2580.04 & 2580.35 & 2580.01 & 2579.20 \\
Objective wool traits & & & & & & \\
GFW & -2154.58 & -2141.26 & -2135.31 & -2138.28 & $\mathbf{- 2 1 3 2 . 3 5}$ & -2140.58 \\
CFW & -267.346 & -254.012 & -246.262 & -251.568 & $\mathbf{- 2 4 3 . 5 3 3}$ & -254.328 \\
CY & $\mathbf{- 3 4 2 4 . 3 7}$ & -3423.76 & 3423.44 & -3423.76 & -3423.11 & -3424.35 \\
SL & $\mathbf{- 8 7 3 0 . 0 7}$ & -8730.07 & -8729.02 & -8730.03 & N/C & -8730.03 \\
SS & $\mathbf{- 2 4 5 0 . 7 7}$ & -2450.77 & N/C & -2450.76 & N/C & -2450.76 \\
FD & $\mathbf{- 4 9 2 6 . 9 1}$ & -4924.16 & $\mathbf{- 4 9 2 2 . 8 6}$ & -4924.16 & -4922.86 & -4926.27 \\
CVFD & $\mathbf{- 7 8 1 3 . 5 3}$ & -7813.53 & N/C & -7813.53 & N/C & -7813.53 \\
SDFD & $\mathbf{1 6 8 9 . 4 0}$ & 1689.40 & N/C & 1689.39 & N/C & 1689.40
\end{tabular}

FEC: faecal worm egg count; GFW: greasy fleece weight; CFW: clean fleece weight; CY: clean yield; SL: staple length; SS: staple strength; FD: fibre diameter; CVFD: coefficient of variation of fibre diameter; SDFD: standard deviation of fibre diameter; N/C: not significant.

Genetic parameters for FEC and wool traits are presented in Table 3. FEC was heritable regardless of the type of transformation applied to datasets (Table 3). The present heritability $\left(\mathrm{h}^{2}\right.$ ) estimates ranged from 0.10 for untransformed data to 0.16 for log-transformed data. The present range coincides with the corresponding range of 0.14 for untransformed FEC to 0.18 for log-transformed FEC reported earlier using data of the same Merino resource flock (Cloete et al., 2007). The $\mathrm{h}^{2}$ estimates in this investigation for FEC are lower than the averaged value of 0.27 derived from a mixture of naturally and artificially challenged sheep datasets (Safari et al., 2005). The present $h^{2}{ }_{a}$ estimate for untransformed FEC data of 0.10 is lower than the estimate of 0.19 for South African Afrino sheep exposed to 4000 - 6000 artificial Haemonchus contortus infective larvae challenge (Snyman, 2007).

The cube-root-transformed FEC data yielded $\mathrm{a} \mathrm{h}^{2}{ }_{\mathrm{a}}$ of 0.15 , which is on the lower boundary of a range of 0.15 to 0.70 (all cube root transformed) from literature values (Greeff \& Karlsson, 1998; Greeff et al., 1999; Woolaston \& Windon, 2001; Khusro et al., 2004; Pollott et al., 2004; Huisman et al., 2008; Afolayan et al., 2009; Brown et al., 2010), the lowest being found in Merino flocks experiencing similar challenges and Mediterranean climatic conditions to those used in the current study (Greeff et al., 1999). Most of the comparable studies, however, did not indicate the method of challenge, and were conducted on industry datasets. Because FEC was counted at a relatively low accuracy of 100 eggs per gram of wet faeces, this could have contributed to the observed lower $h_{a}^{2}$ estimates. The FEC $(\log +100)$ data yielded an $h^{2}$ estimate of 0.16 for FEC in the present study. This value is lower than the estimate of 0.24 reported in a South African Merino flock (Nieuwoudt et al., 2002). Morris et al. (2005) reported a higher $\mathrm{h}_{\mathrm{a}}^{2}$ estimate of 0.22 at 22 weeks of age and a comparable value of 0.16 at 30 weeks of age in naturally challenged Perendale sheep in New Zealand. Yadav et al. (2006) also reported a higher value of 0.24 for Muzaffarnagari sheep. Raimundo et al. (2009) reported a range of $0.04-0.27$ and $0.01-0.52$ for Santa Ines lambs exposed to natural challenge on 
two separate occasions. The $\mathrm{h}_{a}^{2}$ estimate reported for Romney sheep selected for resilience/resistance under natural nematode parasite challenge was higher at 0.26 (Morris et al., 2010). More recently, Pickering et al. (2012) reported marginally higher $\mathrm{h}^{2}$ estimates of 0.18 measured in summer and 0.19 measured in autumn for New Zealand dual-purpose sheep breeds. Genetic selection also reduced FEC substantially in an Australian Merino resource flock (Woolaston et al., 1997). Phenotypic and genetic variation of FEC in the current study, as well as in the literature, suggests that worthwhile genetic progress in South African sheep breeds is feasible. Selection for reduced FEC resulted in increased profit in Australia (Greeff et al., 2006), which could be achieved in South Africa if sound data collection procedures are followed, and the timing of sampling for FEC is optimized (Greeff \& Pollott, 2004).

Table 3 (Co)variance components and ratios for faecal worm egg count and objectively measured wool traits in Tygerhoek Merino flock

\begin{tabular}{lcccccccccc}
\hline FEC & $\begin{array}{c}\text { Cube } \\
\text { root } \\
\text { FEC }\end{array}$ & $\begin{array}{c}\text { Log of } \\
(\text { FEC+ } \\
100)\end{array}$ & GFW & CFW & CY & SL & SS & FD & CVFD & SDFD \\
\hline
\end{tabular}

\begin{tabular}{|c|c|c|c|c|c|c|c|c|c|c|c|}
\hline \multicolumn{12}{|c|}{ (Co)variance components } \\
\hline$\sigma_{a}^{2}$ & 113428 & 2.06 & 0.024 & 0.24 & 0.22 & 11.44 & 35.29 & 29.30 & 1.12 & 3.43 & 0.16 \\
\hline$\sigma_{m}^{2}$ & & - & - & 0.06 & 0.04 & - & - & - & 0.06 & - & - \\
\hline$\sigma_{p e}^{2}$ & & - & - & 0.03 & 0.02 & - & - & - & - & - & - \\
\hline$\sigma_{a m}$ & & - & - & -0.06 & -0.04 & - & - & - & -0.06 & - & - \\
\hline$\sigma_{e}^{2}$ & 1004740 & 11.84 & 0.126 & 0.46 & 0.23 & 6.89 & 51.81 & 98.90 & 0.62 & 2.23 & 0.10 \\
\hline$\sigma_{p}^{2}$ & 1118200 & 13.91 & 0.15 & 0.76 & 0.45 & 18.33 & 87.10 & 128.20 & 1.74 & 5.70 & 0.26 \\
\hline \multicolumn{12}{|c|}{ Variance ratios } \\
\hline$h_{a}^{2}$ & 0.10 & 0.15 & 0.16 & 0.46 & 0.49 & 0.62 & 0.40 & 0.23 & 0.65 & 0.60 & 0.62 \\
\hline SE & 0.02 & 0.01 & 0.02 & 0.04 & 0.04 & 0.02 & 0.03 & 0.03 & 0.04 & 0.03 & 0.03 \\
\hline $\mathrm{h}_{\mathrm{m}}^{2}$ & - & - & - & 0.07 & 0.08 & - & - & - & 0.03 & - & - \\
\hline SE & - & - & - & 0.02 & 0.03 & - & - & - & 0.01 & - & - \\
\hline $\mathrm{c}_{\mathrm{pe}}^{2}$ & - & - & - & 0.04 & 0.04 & - & - & - & - & - & - \\
\hline SE & - & - & - & 0.02 & 0.02 & - & - & - & - & - & - \\
\hline $\mathrm{r}_{\mathrm{am}}$ & - & - & - & -0.56 & -0.52 & - & - & - & -0.24 & - & - \\
\hline SE & - & - & - & 0.09 & 0.08 & - & - & - & 0.11 & - & - \\
\hline
\end{tabular}

FEC: faecal worm egg count; GFW: greasy fleece weight; CFW: clean fleece weight; CY: clean yield; SL: staple length; SS: staple strength; FD: fibre diameter; CVFD: coefficient of variation of fibre diameter; SDFD: standard deviation of fibre diameter.

$\sigma_{2}^{2}$ : direct additive genetic variance; $\sigma_{\mathrm{m}}^{2}$ : maternal additive genetic variance; $\sigma_{\mathrm{pe}}^{2}$ : permanent environmental variance; $\sigma^{2}$ : residual variance; $\sigma_{p}^{2}$ : total phenotypic variance; $\sigma_{a m}$ : covariance between direct and maternal additive genetic effects; $h_{a}^{2}$ : direct heritability; $h_{m}^{2}$ : maternal heritability; $r_{a m}$ : genetic correlation between direct and maternal additive genetic effects.

Objective wool traits have been studied in the past and were reviewed recently by Safari et al. (2005). Studies included in that review and Matebesi et al. (2009) will be cited only if they are highly comparable with the current study. Wool weights were highly heritable at 0.46 for GFW and 0.49 for CFW in the current study, and were within the range of literature values. Current estimates accord well with those reported by Safari et al. (2007b; 0.46 for GFW and 0.42 for CFW), in which they emphasized a preciseness of their estimated values owing to the pooling of records from a number of Australian Merino resource flocks. Contrary to this study, Brown et al. (2010) reported a higher $\mathrm{h}^{2}$ a range of 0.66 to 0.74 for GFW in Australian Merinos from a combination of two-trait analyses. CY was highly heritable at 0.65 . The current $h^{2}$ value is consistent with the previous estimates in the same Merino flock (Naidoo et al., 2004; Matebesi et al., 2009). Crossbred ewes had a lower $h^{2}$ of 0.53 for $C Y$ when two-trait analyses were involved (Afolayan et al., 2009). Studies on the major four representative strains of Australian Merino sheep yielded a lower $h^{2}$ estimate of 0.54 for $C Y$ (Mortimer et al., 2009). 
Fibre diameter, the primary determinant of wool price (Purvis, 1995; Purvis \& Swan, 1999), was highly heritable at 0.66 in the current study. The current $h^{2}{ }_{a}$ estimate is higher than the weighted mean value of 0.59 derived from a number of literature estimates (Safari et al., 2005). A very high $\mathrm{h}^{2}$ a value of 0.92 was obtained from two-trait analyses involving crossbred ewes (Afolayan et al., 2009). Two measures of FD (CVFD and SDFD) were highly heritable at 0.60 and 0.62 , respectively. The current $h^{2}$ estimate of 0.23 for SS is lower than the weighted mean of 0.34 derived from literature values (Safari et al., 2005) and the range of values amounting to between 0.33 and 0.47 from recent studies on South African and Australian Merino sheep (Matebesi et al., 2009; Mortimer et al., 2009; Brown et al., 2010). SL seemed to be moderately heritable at 0.41 . The current $h^{2}$ estimate accords well with those estimated earlier on the same Merino resource flock, as well as the weighted mean estimated for wool sheep (Safari et al., 2005; Huisman et al., 2008; Matebesi et al., 2009; Mortimer et al., 2009; Brown et al., 2010).

The two wool weight traits were dependent on maternal genetic effects, amounting to 0.07 for GFW and 0.08 for CFW. These values are within the range of values obtained from the literature. The estimate of $\mathrm{h}_{\mathrm{m}}^{2}$ accounted for $2 \%$ for FD in the present study, which is similar to the estimate reported for Australian Merinos (Huisman et al., 2008). Brown et al. (2005) did not find any maternal influence on FD. These results indicated that maternal effects are not that important as far as the expression of FD is concerned. Corresponding $\mathrm{c}^{2}$ pe effects accounted for $4 \%$ of the total phenotypic variance for both fleece weight traits, which was slightly lower than the value of 0.05 estimated earlier (Matebesi et al., 2009). The results from the present study, those of Safari et al. (2007b), and those of Matebesi et al. (2009) suggest that $h_{m}^{2}$ is generally more important than $\mathrm{c}^{2}{ }_{\mathrm{pe}}$ when wool traits of 16 -month Merino sheep are considered.

The significant and negative correlations between direct and maternal genetic effects $\left(r_{a m}\right)$ were estimated at $-0.30,-0.56$ and -0.59 for FD, GFW and CFW, respectively (Table 3). Previous $r_{a m}$ estimates on the same Merino resource flock were higher at -0.65 for GFW and -0.70 for CFW (Matebesi et al., 2009). However, Huisman et al. (2008) reported lower values of -0.29 for GFW and -0.35 for CFW using a comparatively larger dataset. The differences between studies may be because the model reported on their analysis did not include $c^{2}$ pe effects, even though it was the best model according to the log likelihood ratio test. In their analysis, Huisman et al. (2008) indicated that the model that fitted fewer parameters and gave sensible results was preferred over other models based on the Bayesian information criterion value.

The relationships between FEC ( $\mathrm{Log}+100)$ and objectively measured wool traits from two-trait analysis will be presented and discussed in the section on genetic correlations. The outcome of analyses involving cube root transformed FEC closely corresponded with those involving log transformed FEC, making the presentation of both sets of results superfluous. Therefore the estimates of genetic, phenotypic and environmental correlations between FEC (Log+100) and objectively measured wool traits are presented in Table 4. Wool weights were genetically unfavourable related to FEC. The magnitude of all genetic correlations, however, was lower than $20 \%$ in all cases, and did not reach significance (i.e. below double the corresponding standards error). An average $r_{g}$ of 0.00 for wool weight with FEC was derived from four

Table 4 Correlations between faecal worm egg count and objectively measured wool traits in Tygerhoek Merino flock

\begin{tabular}{lrrr}
\hline Trait & Genetic $\left(r_{\mathrm{g}}\right)$ & Environment $\left(r_{\mathrm{e}}\right)$ & Phenotypic $\left(r_{\mathrm{p}}\right)$ \\
\hline FEC $($ log+100) with: & & & \\
GFW & $0.173 \pm 0.095$ & $0.011 \pm 0.022$ & ${ }^{*} 0.040 \pm 0.014$ \\
CFW & $0.155 \pm 0.095$ & $0.027 \pm 0.022$ & $* 0.051 \pm 0.014$ \\
CY & $0.053 \pm 0.073$ & $-0.016 \pm 0.027$ & $0.007 \pm 0.015$ \\
SL & $-0.006 \pm 0.088$ & $-0.014 \pm 0.025$ & $-0.009 \pm 0.016$ \\
SS & ${ }^{*}-0.540 \pm 0.103$ & $* 0.079 \pm 0.026$ & ${ }^{*}-0.036 \pm 0.014$ \\
FD & $-0.091 \pm 0.078$ & $-0.003 \pm 0.029$ & $-0.029 \pm 0.016$ \\
CVFD & $* 0.326 \pm 0.072$ & $-0.052 \pm 0.027$ & $* 0.060 \pm 0.015$ \\
SDFD & $* 0.253 \pm 0.073$ & $-0.057 \pm 0.030$ & $* 0.043 \pm 0.015$ \\
\hline
\end{tabular}

FEC (Log+100): log transformed data + 100 to cater for 0 GFW: greasy fleece weight; CFW: clean fleece weight; CY: clean yield; SL: staple length; SS: staple strength; FD: fibre diameter; CVFD: coefficient of variation of fibre diameter SDFD: standard deviation of fibre diameter.

* Significant correlation. 
literature values in a review by Safari et al. (2005). A previous study on the same Merino resource flock yielded a $r_{g}$ estimate of 0.19 between FEC and CFW (Cloete et al., 2007), which is slightly higher than the value of 0.16 derived in the current study. The results of genetic relationships of FEC with wool weights obtained from the current study are in line with those reported in Australian Merinos pertaining to sign and magnitude (Khusro et al., 2004), with the exception of the estimated $r_{g}$ of -0.01 between CFW and FEC at the hogget stage in the study by Khusro et al. (2004). Similar values were estimated for the $r_{g}$ of FEC with GFW (0.15) and CFW (0.13) in Australian Merinos (Pollott \& Greeff, 2004). A recent study in New Zealand dual-purpose sheep breeds (Pickering et al., 2012) also reported unfavourable $r_{g}$ estimates for fleece weight with FEC at 12 months in summer (0.11) and in autumn (0.17). CY was unfavourably related to FEC in absolute terms, but the estimate was smaller than the corresponding standard error. No comparable estimates were found in the literature.

The results from the present study suggested that FD was unfavourably genetically related to FEC $0.09 \pm 0.08$ - but the estimate was not significant. Previous studies on Merino sheep reported the same inferences (Khusro et al., 2004; Pollott \& Greeff, 2004; Safari et al., 2005; Cloete et al., 2007) following a very low range of $r_{g}$ estimates $(-0.05$ to 0.01$)$ derived from genetic studies involving FD and FEC. Two measures of variation in FD (CVFD and SDFD) were positively related to log transformed FEC at genetic level. A positive $r_{g}$ is favourable in this instance, as lower values are striven for FEC, as well as in CVFD and SDFD. A similar result was obtained for the $r_{g}$ of log transformed FEC with CVFD in a previous study on the same Merino resource flock (Cloete et al., 2007). The current $r_{g}$ estimates of 0.33 for CVFD and 0.25 for SDFD are higher than those (0.09 and 0.10) reported by Greeff \& Karlsson (1998), as well as the value of -0.05 reported by Greeff \& Karlsson (1999) between FEC and CVFD. Favourable phenotypic relationships were observed between FEC and CVFD, as well as SDFD. These results suggested a reduced CVFD in animals with a lower FEC. It is evident from the current results that environmental effects affecting FEC do not affect measures of FD conclusively. Similar results were reported between FEC and CVFD in South African Merinos (Cloete et al., 2007). No comparable results were found for correlations of FEC with SDFD.

The $r_{g}$ of FEC with SS was comparatively high and negative in sign in the current study at $>-0.50$ (Table 4). Studies in Australian Merinos yielded a lower $r_{g}$ estimate of -0.20 where regression analysis was used (Greeff \& Pollott, 2004). Cloete et al. (2007) reported a similar $r_{g}$ estimate of -0.49 using the same Merino flock. However, these results suggested that SS may be improved when animals are selected for a reduced FEC. At genetic level, SL was favourably related to FEC in absolute terms, although the correlations were very small with high standard errors. Studies in Australian Merinos also yielded a favourable relationship that was below $10 \%$ in magnitude (Greeff \& Karlsson, 1998). The results from the literature and obtained in the current study suggested that no detrimental effect is likely on SL if selection for FEC is included in Merino sheep breeding objectives when worm infestations may lower productivity.

Phenotypic and environmental correlations between wool weight and FEC (Log+100) were unfavourable but low. This is consistent with the values obtained from the literature (Khusro et al., 2004; Pollott \& Greeff, 2004; Safari et al., 2005) with few exceptions. CY was unfavourable related to FEC at both $r_{p}$ and $r_{e}$ levels. Attempts to find comparable estimates from the literature were not successful. Therefore the results from the current study, as well as those reported in the literature, suggested that wool weights could be reduced if selection for reduced FEC were being practised.

\section{Conclusions}

Internal parasite infestations constitute a health problem to domestic livestock. The present study suggested that FEC is variable and heritable, and that selection should result in additive gains in the ability of animals to resist nematode infestation in South Africa. Significant additive genetic gains in FEC accrued in Australian Rylington Merinos (Karlsson \& Greeff, 2006), resulting in a decline of nematode eggs from individual sheep. However, Karlsson \& Greeff (2001) indicated that optimum procedures need to be followed for FEC to be included in breeding programmes. Selection for a reduced FEC is unlikely to result in unfavourable correlated responses in objectively measured wool traits in South African Merinos, as suggested by generally favourable genetic relationships of wool traits with FEC. Two important determinants of wool price, namely SS and FD, were generally favourably related to FEC in the present study. The exception to this trend was observed for wool weight traits, where FEC was unfavourably related to both GFW and CFW. This antagonistic relationship between wool weight and FEC was also observed in New Zealand (Bisset et al., 2011). However, the magnitude of these relationships in the current study is such that it ought to be feasible to simultaneously improve FEC and wool weights. Apart from being variable and heritable, FEC is practical to record in a well-equipped laboratory for counts, less expensive compared to losses due to nematode infestation, and simple to conceptualize. Identification of individuals that are resistant to nematode infestation is essential to conserve genotypes later that are adapted to various South African environments, which could be useful in future developments in small ruminant production. 


\section{Acknowledgements}

Tygerhoek technical staff and farm workers responsible for FEC are gratefully acknowledged. Financial support for this study was provided by THRIP funding of NRF, NRF, the National University of Lesotho, Organization for Women in Science for the Developing World (OWSDW) and CIVA Innovation Management.

\section{References}

Afolayan, R.A., Fogarty, N.M., Morgan, J.E., Gaunt, G.M., Cummins, L.J. \& Gilmour, A.R., 2009. Preliminary genetic correlations of milk production and milk composition with reproduction, growth, wool traits and worm resistance in crossbred ewes. Small Rumin. Res. 82, 27-33.

Amer, P.R., Woolaston, R.R., Eady, S.J. \& McEwan, J.C., 1997. Economic values for sheep internal parasite resistance traits in New Zealand and Australia. Proc. Assoc. Advmt. Anim. Breed. Genet. 13, 504-507.

Bisset, S.A. \& Morris, C.A., 1996. Feasibility and implications of breeding sheep resilience to nematodes challenge. Int. J. Parasit. 26, 856-868.

Bisset, S.A., Vlassof, A., Morris, C.A., Sothey, B.R., Baker, R.L. \& Paker, A.G.H., 1992. Heritability of and genetic correlations among faecal egg counts and productivity traits in Romney sheep. N. Z. J. Agric. Res. 35, 51-58.

Bisset, S.A., Van Wyk, J.A., Bath, G.F., Morris, C.A., Stenson, M.O. \& Malan, F.S., 2001. Phenotypic and genetic relationships among FAMACHA score, faecal egg count and performance data in Merino sheep exposed to Haemonchus contortus infection in South Africa. Proc. $5^{\text {th }}$ Int. Sheep Vet. Congress, Cape Town South Africa. CD-communication.

Bisset, S.A., Morris, C.A., McEwan, J.C. \& Vlassof, A., 2011. Breeding sheep in New Zealand that are less reliant on anthelmintics to maintain health and productivity. N. Z. J. Vet. Parasit. 49, 236-246.

Brown, D.J. \& Tier, B., 2003. Alternate methods for estimating breeding values for faecal egg count data from Merino studs across Australia. Proc. Assoc. Advmt. Anim. Breed. Genet. 15, 115-118.

Brown, D.J., Atkins, K. \& Huisman, A.E., 2005. Expression of body weight, fleece weight and fibre diameter in across flock genetic evaluation. Proc. Assoc. Advtm. Anim. Breed. Genet. 16, 84-87.

Brown, D.J., Swan, A.A. \& Gill, J.S., 2010. Within- and across-flock genetic relationships for breech flystrike resistance indicator traits. Anim. Prod. Sci. 50, 1060-1068.

Chauhan, K.K., Rout, P.K., Mandal, A., Singh, S.K. \& Roy, R., 2003. Genetic resistance of Barbari and Jamunapari kids to natural infection with gastrointestinal nematodes. Trop. Anim. Hlth. Prod. 35, 397-408.

Cloete, S.W.P., 1986. A study of phenotypic and genetic aspects of reproduction in the Tygerhoek Merino flock. M.Sc. thesis, University of Stellenbosch, Stellenbosch, South Africa.

Cloete, S.W.P., Dreyer, F.H. \& Du Toit, E., 2000. Faecal nematode egg count in Merino sheep following natural challenge. S. Afr. J. Anim. Sci. 30 (Suppl. 1), 24-25.

Cloete, S.W.P., Olivier, J.J., Du Toit, E. \& Dreyer, F.H., 2007. Genetic analysis of faecal worm egg count in South Africa Merinos under natural challenge. S. Afr. J. Anim. Sci. 37, 237-247.

Doyle, E.K. \& Eady, S.J., 2001. Alternate approaches to presentation of worm resistance breeding values for Australian sheep. Proc. Assoc. Advmt. Anim. Breed. Genet. 14, 195-198.

Duguma, G., 2002. A genetic study of early growth traits and ewe productivity in Merino sheep. M.Sc. thesis, University of Stellenbosch, Stellenbosch, South Africa.

Eady, S.J., 1995. Implications of non-normal distribution of faecal egg count for measuring worm resistance in Merino sire evaluation schemes. Proc. Aust. Assoc. Anim. Breed. Gen. 11, 79-83.

Gilmour, A.R., Gogel, B.J., Cullis, B.R., Welham, S.J. \& Thompson, R., 2009. ASREML-User Guide Release 3.0 VSN International Ltd, Hemel Hempstead, HPI IES, UK.

Gray, G.D., 1991. Breeding for resistance to trichostrongyle nematodes in sheep. In: Breeding for Disease Resistance in Farm Animals. Eds: Owen, J.B. \& Oxford, R.F.E., CAB Int. Wallingford. pp. 187-200.

Heydenrych, H.J., 1975. 'n Studie van kudde statistieke, nie-genetiese faktore, genetiese parameters en seleksievordering met betrekking tot die Tygerhoek Merinokudde. Ph.D. proefskrif, Universiteit van Stellenbosch, Stellenbosch, Suid-Africa.

Heydenrych, H.J., Du Plessis, J.J. \& Cloete, S.W.P., 1984. Increasing the wool production of Merino sheep in South Western Districts of South Africa by direct and indirect selection. Proc. $2^{\text {nd }}$ World Congr. Sheep Beef Cattle Breed. 16-19 April 1984, Pretoria. Eds: Hofmeyr, J.H. \& Meyer, E.H.H., South African Stud Book and Livestock Improvement Association, Bloemfontein (1984), 399-412.

Huisman, A.E. \& Brown, D.J., 2008. Genetic parameters for bodyweight, wool, disease resistance and reproduction traits in Merino sheep. 2. Genetic relationships between body weight and other traits. Aust. J. Exp. Agric. 48, 1186-1193. 
Greeff, J.C. \& Karlsson, L.J.E., 1998. The genetic relationship between faecal consistency, faecal worm egg counts and wool traits in Merino sheep. Proc. $6^{\text {th }}$ Wrld Congr. Gen. Appl. Livest. Prod. Armidale, Australia, 24, 63-66.

Greeff, J.C. \& Karlsson, L.J.E., 1999. Will selection for decreased faecal worm egg count result in an increase in scouring? Proc. Assoc. Advmt. Anim. Breed. Genet. 13, 508-511.

Greeff, J.C., Karlsson, L.J.E. \& Harris, J.F., 1995. Heritability of faecal worm egg count at different times of the year in a Mediterranean environment. Proc. Aust. Assoc. Anim. Breed. Gen. 11, 117-121.

Greeff, J.C., Karlsson, L.J.E. \& Besier, R.B., 1999. Breeding sheep for resistance to internal parasites. In: Rising to the challenge-Breeding for $21^{\text {st }}$ Century Consumer. Beef industry and CRC for Premium Quality Wool Industry Simposia. Proc. Aust. Assoc. Anim. Breed. Genet. 13, 150-155.

Greeff, J.C., Karlsson, L.J.E. \& Underwood, N., 2006. Breeding Merino sheep for worm resistance increases profit in a Mediterranean environment. Proc. $8^{\text {th }}$ Wrld Congr. Gen. Appl. Livest. Prod., Bello Horizonte, Brazil. Communication 15-08.

Karlsson, L.J.E., 1999. Sustainable sheep ectoparasite control using IPM. Proc. Aust. Sheep Vet. Assoc. Conf. 128-133.

Karlsson, L.J.E. \& Greeff, J.C., 2001. Response to selection for resistance to sheep nematodes. Proc. $5^{\text {th }}$ Int. Sheep Congr. 170-171.

Karlsson, L.J.E. \& Greeff, J.C., 2006. Selection response in faecal worm egg counts in the Rylington Merino parasite resistant flock. Aust. J. Exp. Agric. 46, 809-811.

Karlsson, L.J.E., Greeff, J.C. \& Harris, J.F., 1995. Genetic trends in selection line for low faecal worm egg count. Proc. Aust. Assoc. Anim. Breed. Genet. 11, 122-125.

Khusro, M., Van der Werf, J.H.J., Brown, D.J. \& Ball, A., 2004. Across flock (co)variance components for faecal worm egg count, live weight, and fleece traits in Australian Merinos. Livest. Prod. Sci. 91, 35-43.

Mandal, A. \& Sharma, D.K., 2008. Inheritance of faecal nematode egg count in Barbari goats following natural Haemonchus contortus infection. Vet. Parasit. 155, 89-94.

Mandonnet, N., Aumont, G., Fleury, R., Varo, H., Gruner, L., Bouix, J. \& Vu Tien Khangs, J., 2001. Assessment of genetic variability of resistance to gastrointestinal nematode parasites in Creole goats in humid tropics. J. Anim. Sci. 79, 1706-1702.

Matebesi-Ranthimo, P.A., 2007. Genetic parameters for subjective and objective wool and body traits in the Tygerhoek Merino flock. M.Sc. thesis, University of Free State, Bloemfontein, South Africa.

Matebesi, P.A., Cloete, S.W.P. \& Van Wyk, J.B., 2009. Genetic parameter estimation of 16-month live weight and objectively measured wool traits. S. Afr. J. Anim. Sci. 39, 73-82.

Matika, O., Pong-Wong, R., Woolliams, J.A. \& Bishop, S.C., 2010. Confirmation of two quantitative trait loci regions for nematode resistance in commercial British terminal sire breeds. The Animal Consortium 2011, 1-8.

Morris, C.A., 2011. Review of genetic parameters for disease resistance in sheep in New Zealand and Australia. Proc. Assoc. Advmt. Anim. Breed. Genet. 18, 263-271.

Morris, C.A., Clarke, J.N., Watson, T.G., Wrigglesworth, A.L. \& Dobbie, J.L., 1996. Faecal egg count and food intake comparison of Romney single-trait selection and control lines. N. Z. J. Agric. Res. 39, 371-378.

Morris, C.A., Bisset, S.A., Vlassoff, A., Baker, R.L., Watson, T.G. \& Wheeler, M., 1997. Yearling and ewe fleece weights in Romney and Perendale flocks selected for divergence in faecal nematode egg count. Proc. Assoc. Advmn. Anim. Breed. Genet. 12, 50-53.

Morris, C.A., Wheeler, M., Watson, T.G., Hosking, B.C. \& Leathwick, D.M., 2005. Direct and correlated response to selection for high or low faecal nematode egg count in Perendale sheep. N. Z. J. Agric. Res. 48, 1-10.

Morris, C.A., Wheeler, M. \& Shaw, R.J. 2010. Correlated responses following genetic selection to change faecal egg count in Romney. N. Z. Soc. Sci. 70, 229-234.

Mortimer, S.I., Robinson, D.L., Atkins, K.D., Brien, F.D., Swan, A.A., Taylor, P.J. \& Fogarty, N.M., 2009. Genetic parameters for visually assessed traits and their relationships to wool production and liveweight in Australian Merino sheep. Anim. Prod. Sci. 49, 32-42.

Naidoo, P., Cloete, S.W.P. \& Olivier, J.J., 2004. Heritability estimates and correlations between subjectively assessed and objectively measured fleece traits in Merino sheep. S. Afr. J. Anim. Sci. 34, 38-40.

Nieuwoudt, S.W., Theron, H.E. \& Krüger, L.P, 2002. Genetic parameters for resistance to Haemonchus contortus in Merino sheep in South Africa. J. S. Afr. Med. Assoc. 73, 4-7.

Olayemi, M.E., Walkden-Brown, S.W., Van der Werf, J.H.J. \& Le Jambre, L.F., 2001. Preliminary analysis of sire effects on resistance to gastrointestinal nematode infection in Angora and Cashmere goats. Proc. Assoc. Advmt. Anim. Breed. Genet. 14, 203-206. 
Perry, B.D., Randolph, T.F., McDermott, J.J., Sones, K.R. \& Thornton, P.K., 2002. Investing in animal health research to alleviate poverty. Internal Livestock research institute, Nairobi, Kenya. 148 pp.

Pickering, N.K., Dodds, K.G., Blair, H.T., Hickson, R.E., Johnson, P.L. \& McEwan, J.C., 2012. Genetic parameters for production traits in New Zealand dual-purpose sheep, with an emphasis on dagginess. J. Anim. Sci. 90, 1411-1420.

Pocock, M.J., Eady, S.J. \& Abbott, K.A., 1995. Nemesis in action - Breeding for worm resistance. Proc. Aust. Assoc. Anim. Breed. Genet. 11, 74-78.

Purvis, I.W., 1995. Strategies for improving wool quality and productivity in fine and superfine woolled Merino flocks. Proc. Aust. Assoc. Anim. Breed. Genet. 11, 510-515.

Purvis, I.W. \& Swan, A.A., 1999. Incorporating assessed style, length and strength into breeding objectives for fine and superfine Merino flocks. Proc. Assoc. Advmt. Anim. Breed. Genet. 13, 177-180.

Pollot, G.E. \& Greeff, J.C., 2004. Genotype x environment interactions and genetic parameters for fecal worm egg counts and production traits of Merino sheep. J. Anim. Sci. 82, 2840-2851.

Pollott, G.E. \& Karlsson, L.J.E., 2004. Genotype x environmental interactions and genetic parameters for faecal worm egg counts and production traits of Merino sheep. J. Anim. Sci. 82, 2840-2851.

Pollott, G.E., Karlsson, L.J.E., Eady, S. \& Greeff, J.C., 2004. Genetic parameter for indicators of host resistance to parasites from weaning to hoggets age in Merino sheep. J. Anim. Sci. 82, 2852-2864.

Raimondo, N.B., Lôbo, L.S., Vieira, A.A., De Oliveira, E., Muniz, N. \& Da Silva, J.M., 2009. Genetic parameters for faecal egg count, packed cell volume and body-weight in Santa Inês lambs. Genet. Mol. Biol. 32, 288-294.

Reynecke, D.P., Van Wyk, J.A., Gummow, B., Dorny, P. \& Boomker, J., 2011. Stochastic model accommodating FANACHA ${ }^{\odot}$ system for estimating worm burden and associated risk factors in sheep naturally infected with Haemonchus contortus. Vet. Parasitol. 177, 231-241.

Safari, E., Fogarty, N.M. \& Gilmour, A.R., 2005. A review of genetic parameter estimates for wool, growth, meat and reproduction traits in sheep. Livest. Prod. Sci. 92, 271-289.

Safari, E., Fogarty, N.M., Gilmour, A.R., Atkins, K.D., Mortimer, S.I., Swan, A.A., Brien, F.D., Greeff, J.C. \& Van der Werf, J.H.J., 2007. Across population genetic parameters for wool, growth, and reproduction traits in Australian Merino sheep. 2. Estimates of heritability and variance components. Aust. J. Agric. Res. 58, 177-184.

Snyman, M.A., 2007. Prospects for the utilization of variation in parasite resistance among individual sheep within a flock. Grootfontein Agric. 7 (1), 29-34.

Swalve, H.H., 1993. Estimation of direct and maternal (co)variance components for growth traits in Australian Simmental beef cattle. J. Anim. Breed. Genet. 110, 241-252.

Vaez Torshizi, R., Nicholars, F.W. \& Raadsma, H.W., 1996. REML estimates of variance and covariance components for production traits in Australian Merino sheep, using an animal model. 1 Body weight from birth to 22 months. Aust. J. Agric. Res. 47, 1235-1249.

Van Schalkwyk, L.W., Schroeder, P.C., Malan, F.S. \& Van Wyk, J.A., 1994. McMaster method of faecal worm egg count. In: Worm workshop: Recommendations on worm control. pp. 19-21.

Van Wyk, J.A. \& Bath, G.F., 2002. The FAMACHA system for managing haemonchosis in Sheep and goats by clinically identifying individual animal for treatment. Vet. Res. 33, 509-529.

Van Wyk, J.B., Fair, M.D. \& Cloete, S.W.P., 2003. Revised models and genetic parameter estimates for production and reproduction traits in the Elsenburg Dormer sheep stud. S. Afr. J. Anim. Sci. 33, 213-222.

Vatta, A.F., Krecek, R.C., Du Plessis, A., Havemann, A.R. \& Van der Merwe, J.S., 2000. Workshops propose national program for veterinary helminthology in South Africa. J. S. Afr. Vet. Assoc. 71, 2-5.

Vattaa, A.F. \& Lindberg, A.L. 2006. Managing anthelmintic resistance in small ruminant livestock of resourcepoor farmers in South Africa. J. S. Afr. Vet. Assoc. 77, 2-8.

Woolaston, R.R. \& Piper, L.R., 1996. Selection of Merino sheep for resistance to Haemonchus contortus: Genetic variation. Anim. Sci. 62, 451-460.

Woolaston, R.R. \& Window, R.G., 2001. Selection of sheep for response to Trichostrongylus colubriformis lavae: Genetic parameters. Anim. Sci. 73, 41-48.

Woolaston, R.R. \& Barger, I.A. \& Eady, S.J., 1997. The relative effectiveness of alternative worm control measures and their interactions. Proc. Assoc. Advmt. Anim. Breed. Genet. 12, 45-49.

Yadav, N.K., Mandal, A., Sharma, D.K., Rout, P.K. \& Roy, R., 2006. Genetic studies on faecal egg count and packed cell volume following natural Haemonchus contortus infection and their relationships with liveweight in Muzaffarnagari sheep. Asian-Austral. J. Anim. Sci. 19, 1525-1528.

Zhang, Y.D., Crook, B.J. Gray, G.D. \& Fogarty, N.M., 1997. Resistance of meat sheep genotypes to naturally acquired worm infections. Proc. Assoc. Advmt. Anim. Breed. Genet. 12, 309-312. 